\title{
Die Meisterprüfung im Elektro-Maschinenbauer-Handwerk
}

\author{
Lehr- und Hilfsbuch \\ für die Vorbereitung zur Meisterprüfung \\ Handbuch für die Mitglieder der \\ Meister-Prüfungskommission \\ von \\ Fritz Raskop \\ Leipzig \\ Sachverständiger für Elektromaschinenbau, \\ speziell für Instandsetzungen an \\ elektr. Maschinen \\ 3. Auflage \\ B erlin W 35 \\ Technischer Verlag Herbert Cram \\ 1947
}


Druck von Otto Walter, Berlin SW 29, UrbanstraBe 71 Reg. Nr. I C B 1066 